\title{
LA DIDÁCTICA DE LA HISTORIA DEL ARTE EN EL SIGLO XVIII: APORTACIONES DE LAS ACADEMIAS
}

\author{
Maria del Mar Bernabé Villodre ${ }^{1}$
}

\section{RESUMEN}

La didáctica de la Historia del Arte debe mucho a los ideales educativos de la Ilustración, que supusieron la organización de las Reales Academias de Bellas Artes. Su aportación al desarrollo de la didáctica de la Historia del Arte fue fundamental por la publicación de tratados artísticos, primitivos "manuales" docentes fundamentales para comprender la metodología didáctica actual. Se pretende demostrar la importancia de las Academias en el desarrollo de la didáctica de la Historia del Arte.

Palabras clave: academias, ilustración, didáctica de la Historia del Arte.

${ }^{1}$ Universitat de València (UV), València, Espanha. 


\section{A DIDÁTICA DA HISTÓRIA DA ARTE NO SÉCULO XVIII: CONTRIBUIÇÕES DAS ACADEMIAS}

\section{RESUMO}

O ensino da História da Arte deve muito aos ideais educacionais do Iluminismo, que levaram à organização das Academias Reais de Belas Artes. Sua contribuição para o desenvolvimento da didática da História da Arte foi fundamental para a publicação de tratados artísticos, "manuais" fundamentais primitivos para entender a metodologia didática atual. Pretende-se demonstrar a importância das Academias no desenvolvimento da didática da História da Arte.

Palavras-chave: academias, ilustração, didática da História da Arte.

\section{THE DIDACTICS OF THE HISTORY OF ART IN THE EIGHTEENTH CENTURY: CONTRIBUTIONS OF THE ACADEMIES}

\section{ABSTRACT}

The teaching of Art History owes much to the educational ideals of the Enlightenment, which led to the organization of the Royal Academies of Fine Arts. His contribution to the development of the didactics of Art History was fundamental for the publication of artistic treatises, primitive fundamental "manuals" to understand the current didactic methodology. It is intended to demonstrate the importance of the Academies in the development of the didactics of Art History.

Keywords: academies, illlustration, didactics of the History of Art.

\section{LA DIDACTIQUE DE L'HISTOIRE DE L'ART AU XVIIIE SIĖCLE: CONTRIBUTIONS DES ACADÉMIES}

\section{RÉSUMÉ}

L'enseignement de l'Histoire de l'Art doit beaucoup aux idéaux pédagogiques des Lumières, qui ont conduit à l'organisation des Académies royales des Beaux-Arts. Sa contribution au développement de la didactique de l'Histoire de l'Art a été fondamentale pour la publication de traités artistiques, "manuels" fondamentaux primitifs pour comprendre la méthodologie didactique actuelle. Il vise à démontrer l'importance des académies dans le développement de la didactique de l'Histoire de l'Art.

Mots-clés: académies, illustration, didactique de l'Histoire de l'Art. 


\section{INTRODUCCIÓN}

La didáctica de la Historia del Arte debe mucho al desarrollo de la Ilustración (siglo XVIII), que con sus ideales educativos llevó a la reorganización de la enseñanza y a la aparición de las Reales Academias de Bellas Artes. En ellas, se estableció el estudio teórico del Arte como garantía de la consideración de "Artista", más allá de su visión como artista práctica, sino como teórico de aquellos conocimientos que podía realizar a nivel especulativo. En estos centros, ya no se trataba tanto de la promoción de obras que comprendiesen la vida de los artistas, sino de vidas de artistas a través de sus obras que permitiesen comprender dicha producción (SCHLOSSER, 1986) y, por tanto, quedase garantizada una figura de artista como persona formada en un sentido más amplio del término.

Durante esta época, se publicaron muchos tratados que pretendían racionalizar las diferentes manifestaciones artísticas, al tiempo que educar al pueblo. La visión del fin de la Historia del Arte no ha cambiado mucho desde aquel momento hasta ahora, puesto que autores como Caballero (1992-1993) han señalado la importancia de adecuar contenidos y procedimientos al interés del alumnado, añadamos que a las necesidades ciudadanas puesto que desde la última reforma educativa se ha venido hablando de "Competencia Cultural y Artística" (LOE) y, recientemente, de "Conciencia y Expresiones Culturales" (LOMCE). El estudio de las referencias a la didáctica de la Historia del Arte en estos primitivos "manuales docentes" será fundamental para comprender la génesis de la didáctica de la Historia del Arte actual. Ahora bien, ċrealmente pueden considerarse útiles para comprender el proceso didáctico actual de la disciplina? ¿Podría hablarse de Historia del Arte como tal en la España del Siglo XVIII? Para ello, han sido analizadas las posibles referencias a una metodología didáctica de la Historia del Arte en las Academias en las principales fuentes literarias artísticas de la época. Todo esto llevó a formular el objetivo principal: 
demostrar la importancia de las Reales Academias de Bellas Artes en el desarrollo histórico de la didáctica de la Historia del Arte. Debe señalarse que, en todo momento, este artículo está tratando de recoger qué proceso de enseñanza/aprendizaje centrado en la formación histórico-artística a nivel teórico se estaba realizando en dichos centros formativos; no en cuanto a la formación práctica y especulativa del artista a través de dichos manuales y tratados teóricos.

\section{ESTADO DE LA CUESTIÓN}

En España, los novatores encabezados por el Padre Tosca con su Compendio de matemáticas y su Arquitectura civil y militar (CÁMARA, 2005), promovieron el avance científico a través de tertulias y en academias privadas: así, surgió la importancia de las Academias como centros difusores del saber frente al dogmatismo universitario. Éstas fomentarían una educación diferente, alejada del medievalismo universitario arraigado en las tradiciones religiosas y alejado del espíritu racional y empírico ilustrado; pero, promoviendo al mismo tiempo un alejamiento de la practicidad reinante en la formación de los artistas y centrándose, también, en la formación teórica como base para la consideración de artista plena.

El permiso por parte del poder político para la creación de asociaciones, academias y distintos centros de formación, reunión y difusión del saber, permitió que los logros técnicos pudiesen ser conocidos y disfrutados por todos (religiosos, aristócratas, burgueses). De ahí que este período fuese decisivo para el asentamiento de la didáctica en disciplinas como la Historia del Arte, que vivió un aumento de obras relacionadas con el Arte que trajeron consigo una profunda revisión historiográfica (GARCÍA LÓPEZ, 2013) que puede considerarse una base para replantearse el proceso de enseñanza/aprendizaje en relación con el mundo artístico, tanto a nivel práctico como teórico. En este contexto, surgieron las Sociedades Económicas de Amigos del País, promovidas 
por Campomanes, y cuyos integrantes pertenecían a la generación del despotismo ilustrado (PALMA, 1984).

Entre las fuentes tratadísticas difundidas, destaca la obra de Valzania (1792), Instituciones de arquitectura, en cuyo prólogo insiste en el aspecto didáctico de la obra para la formación no sólo práctica del artista, sino también teórica. Aunque, si bien menciona esa importancia didáctica no se establece una forma de "difundir" dicho conocimiento teórico, lo que lleva a considerar que el proceso de enseñanza/aprendizaje se realizaba magistralmente.

Otra obra que destaca es el Museo Pictórico y Escala Óptica de Palomino (1715), que incluye importantes referencias didácticas y muestra esa vertiente didáctica cuando en su página inicial comenta las demostraciones filosóficas de los fundamentos de la teoría de la pintura; de modo que, invita a la reflexión y, por tanto, a ahondar en la materia desde ese punto filosóficopedagógico que caracterizaba la enseñanza de la Antigüedad. Es, por tanto, una obra fundamental para conseguir nuestro objetivo. El Tomo V del Compendio Matemático de Tosca (1757) es de gran relevancia didáctica porque al introducir la crítica artística, también, invita a la reflexión y madurez de pensamiento del pueblo. Esa intención didáctica a través de la explicación de las Artes queda constatada con obras como el Teatro Crítico de Feijoo (1778), que dedica un discurso del Tomo IV (originalmente redactado en 1730) a la "Resurrección de las Artes y Apología de los Antiguos". Todos estos tratados tienen algo importante en común: se enfoca el proceso didáctico como un encuentro de reflexión gracias a la crítica artística que se promueve; lo que quiere decir que el futuro artista no sólo podrá representar sus obras artísticas, sino también hablar de ellas, contextualizarlas, explicarlas, fundamentarlas... Se estaría hablando de una pedagogía diferente a la clase magistral, al defenderse la crítica artística como forma de transmitir conocimientos en las Academias.

En una obra en la que puede observarse la línea didáctica, es en el prólogo de Escuela de arquitectura civil de Brizguz (1795), que defiende esa línea didáctica magistral presente desde la Edad Media. De Arce (1786) también 
consideraba que se podía formar a través de la lectura de su obra. Sus Conversaciones sobre la escultura, compendio histórico, teórico y práctico de ella está dedicado a la didáctica, a la formación de los jóvenes, desde el punto de vista de los antiguos griegos: a través del diálogo, de las que denomina "conversaciones" con su hijo. Esta obra aporta un nuevo matiz que permite considerarla un importante punto de inflexión para la evolución de la didáctica histórico-artística de la época. Los artistas tenían estas consideraciones porque en este siglo XVIII abundaban las obras técnicas, teóricas e históricas, con una nueva concepción en la relación teoría-práctica (CASTAÑER, 2013) y, añadamos, formativa. Por tanto, el enfoque didáctico en las clases no podía ser el mismo que en décadas o en siglos anteriores.

Y, en igualdad de importancia estaría el Discurso sobre la educación popular de los artesanos y su fomento de Campomanes (1775), que asienta las bases del ideario educativo: formación ciudadana para la unidad nacional. En esta línea de educación ciudadana, Sánchez de Andrés (2011) ha señalado esa importancia concedida a la formación en Historia del Arte para el ciudadano durante el último tercio del siglo XIX, no sólo como forma de mejorar su cultural general, sino para elevar el nivel de la producción artística del país. Como puede comprobarse, este intento de revalorizar la enseñanza de la Historia del Arte ha venido prolongándose desde hace varios siglos.

Estos tratados serían los más destacados; aunque, deben señalarse importantes obras como las de León y Sanz (1994), Estética y teoría de la arquitectura en los tratados españoles del siglo XVIII, que acercará a otra interpretación más estética de las fuentes ya comentadas. Se han señalado estas obras de arquitectura, principalmente, porque se ha partido de la importancia otorgada en la época por el número de ejemplares publicados, además de porque exposiciones como la del Palacio de Artes Liberales de la Exposición Universal de París de 1889 exhibió materiales didácticos de Historia del Arte, dando lugar a recopilaciones y publicaciones posteriores de autores como Mantz (BLANCO, 1998). Así, se mostraba el importante peso que estos manuales 
tuvieron en el mundo artístico general.

La escasez de obras específicas sobre didáctica de la Historia del Arte, así como de formación en los estudios específicos, han llevado a considerar este tema de gran importancia para el desarrollo de la docencia actual; puesto que los propios expertos en la materia han considerado complicado su proceso de enseñanza, pero, al mismo tiempo, una realidad posible (CALAF, 1996). A pesar de que, las referencias a la didáctica de la Historia del Arte son muy escasas en el siglo pasado (BLANCO, 1984; ÁVILA, 1998, por ejemplo), se observan importantes cambios en estas primeras décadas del siglo XXI: Ávila (2001), Cantonero (2002), Castañeda (2003), Trepat (2005), Candau (2006), Juanola y Calbó (2006), y de Vega (2010).

\section{EL NACIMIENTO DE LAS ACADEMIAS COMO CENTROS DIFUSORES DE LA CULTURA}

La clase aristocrática se negaba a aceptar a los trabajadores mecánicos como "honrados" (MORAL, 1996), porque consideraban que por nacimiento no les correspondía y porque servían a un patrón. Así, la influencia de la Ilustración llevó a organizar centros de formación del artista con una educación más completa que les permitiese ocupar esos mismos puestos de académicosdocentes en dichas instituciones. El propio Winckelmann (1764) señalaba que la Historia del Arte debe enseñar el origen, el desarrollo, la decadencia, la transformación del arte a través de las épocas y de los artistas que lo produjeron, partiendo del propio arte y tratando de evitar afirmaciones banales y descontextualizadas. El artista debía ser formado en el más amplio sentido y, por ello, los manuales formativos debían caracterizarse por buscar una formación estética en el artista, y no sólo una instrumental específica.

Se pueden establecer dos causas para el nacimiento de las Academias en España (ESCUDERO, 1992): el anquilosamiento de la institución universitaria y el interés por establecer instituciones que se preocupasen por el estudio de 
nuevos métodos y ciencias que garantizasen un rigor científico. Estas Academias tenían como objetivos la coordinación y promoción de la investigación en determinados campos de conocimiento; el establecimiento de lazos de unión entre ciencia y tecnología; y la transmisión de dichos conocimientos a la sociedad como forma de mejorar ésta y de garantizar su avance. La difusión de conocimientos que caracterizaba a estos centros se debió también al hecho de que contenían bibliotecas para consulta de profesorado y alumnado, e incluso abiertas al público general (CRESPO, 2007). Estas instituciones se encargaban de regular y controlar la enseñanza artística (HERNÁNDEZ, 2002), lo que era una forma más de intervención ideológica estatal (ARAÑO, 1989); también, se encargaban de la investigación historiográfica y estética. Todo esto permite hablar de una sistematización de la labor pedagógica del proceso artístico, que no había sido considerada hasta la fecha; aunque, esta labor formativa no podía llevarse a cabo si los centros no contaban con material didáctico de apoyo (tratados artísticos). Es decir, que no sólo se formaba a los artistas a nivel práctico, sino también a nivel teórico: lo que dignificó el proceso educativo y al artista.

La monarquía apadrinará las Reales Academias. La Real Academia de Bellas Artes de San Fernando (1752) será la pionera, entre las restantes: la Real Academia de Bellas Artes de San Carlos de Valencia (1768), la Real Academia de Bellas Artes de Santa Isabel de Hungría de Sevilla (1771), la Real Academia de Bellas Artes de Nuestra Señora de las Angustias de Granada (1777), la Real Academia Provincial de Bellas Artes de Cádiz (1778), la Real Academia de Bellas Artes de Santa María de la Arrixaca de Murcia (1779), la Real Academia de Bellas Artes de la Purísima Concepción de Valladolid (1779), y la Real Academia de Bellas Artes de San Luis de Zaragoza (1792). 


\section{LAS ACADEMIAS DE MADRID, VALENCIA, SEVILLA, GRANADA, CÁDIZ, MURCIA, VALLADOLID Y ZARAGOZA}

Durante la Ilustración aparecerán las Reales Academias de Bellas Artes, extendiéndose su aparición hasta el siglo XX (1946). Pero, su aparición y consolidación dio lugar a que se fuesen estructurando las denominadas Escuelas de Artes y Oficios (originarias de las Reales Sociedades Económicas de Amigos del País). El carácter y los objetivos de las Academias de Bellas Artes y de las Escuelas de Arte eran muy diferentes: Tapie (1978) considera que el objetivo de las primeras era fijar una serie de reglas aplicables en distintos géneros, de modo que la aplicación de éstas garantizase que el resultado final pudiese considerarse una obra de arte.

La primera fue la Real Academia de Bellas Artes de San Fernando de Madrid (1752), que recogía las tres artes principales de la época y reflejaba la lucha por la mayor posición del artista pintor entre el resto de artistas (FRANCÉS, 1952); de modo que, su denominación fue "Real Academia de las tres Bellas Artes, Pintura, Escultura y Achitectura, con el nombre de San Fernando”. Mediante su fundación se buscaba acabar con la resistencia artesanal (LÓPEZ; LÓPEZ, 1996), desterrar el sistema gremial (MARTÍN, 1991), para dotar de mayor rango y prestigio al desarrollo artístico al impartir una formación teórica que completase la práctica. A esto, contribuyó el hecho de que se contaba con un amplio perfil de profesionales implicados en la misma, lo que se traducía en situaciones problemáticas entre todo el personal del centro y las personas que participaban de dicha institución (académicos contra consilieros, consejeros contra profesores, etc.), tal como han señalado Bédat (1974) y Úbeda de los Cobos (1987).

Tras unos primeros años orientados a la enseñanza, esta Academia se propuso controlar la teoría y la práctica arquitectónica para evitar abusos en la profesión (CASTILLO; RIAZA, 2001). Pero, la pintura también fue una fuente de preocupación: Goya se sintió especialmente preocupado por la enseñanza de 
la pintura, ya que consideraba que no debía limitarse la libertad del artista ni establecerse el mismo camino educativo para todos los estudiantes (NAVARRETE, 2013); incluso, a riesgo de parecer atrevidos, se podría decir que aquí está asentando las bases de la denominada enseñanza personalizada.

La Real Academia de San Carlos de Valencia (1768) tuvo su antecedente en la Academia de Santa Bárbara, iniciada en 1753 como un tímido intento de poner en marcha los ideales ilustrados en el terreno artístico. Ésta constaba de cuatro secciones: arquitectura, escultura, pintura-grabado y música. Y, en los inicios del siglo XX, tendría tres fines: académico, didáctico y educativo, quedando perfectamente definido el camino iniciado el siglo anterior.

En 1771, se fundará la Real Academia de Bellas Artes de Santa Isabel de Hungría de Sevilla. Es uno de los casos en los que la Academia se funda antes que la Escuela de Artes y Oficios, que tiene su origen en la fundación de la Real Sociedad Económica de Amigos del País (1775) y que no empezó a funcionar hasta 1875 (MONTERO, 2009). La docencia en las primeras academias de dibujo de Sevilla estaba basada en la actitud reflexiva y analítica sobre la creación artística (CORZO, 2011), se promovía algo más que la pura práctica.

La Real Academia de Bellas Artes de Nuestra Señora de las Angustias de Granada (1777), surgió gracias a los espacios educativos artísticos promovidos por las Sociedades Económicas de Amigos del País. Vinculada a ella, en el siglo siguiente aparece la Escuela de Artes y Oficios de Granada.

La Real Academia Provincial de Bellas Artes de Cádiz (1778) contaría con una Escuela Especial de Bellas Artes en el siglo siguiente. Fueron las cofradías de plateros las que quisieron mejorar su formación y promovieron la creación de una escuela de dibujo que les capacitase mejor, y ésta terminaría desembocando en la Academia tras pasar por múltiples transformaciones.

La Real Academia de Bellas Artes de Santa María de la Arrixaca de Murcia (1779) fue creada con el apoyo de la Real Sociedad 
Económica de Amigos del País. Entre sus cometidos estaban la enseñanza y la investigación, que daba lugar a trabajos doctrinales.

La Real Academia de Bellas Artes de la Purísima Concepción de Valladolid (1779) dará lugar en 1851 a la Escuela de Bellas Artes de Valladolid, pionera en la incorporación de las mujeres. Pretendía promocionar y fomentar las artes mediante la enseñanza de materias como las matemáticas y el dibujo; por supuesto, siempre en las limitaciones y orientaciones establecidas por la Real Academia de San Fernando.

En 1792, se establece como Real Academia de las Tres Nobles Artes de San Luis de Zaragoza a la Escuela de Dibujo de esta ciudad. Ésta dependía de la Real Sociedad Económica de Amigos del País. Esta Real Academia impartió enseñanzas de Pintura, Arquitectura, Escultura y Grabado. En el siglo XIX, la Real Academia vio mermadas sus atribuciones docentes al crearse las Escuelas de Bellas Artes (1857), en las que se impartían las enseñanzas artísticas, quedando la Academia para funciones de tipo académico, principalmente.

\section{CARACTERÍSTICAS DE ESTOS CENTROS COMO FORMADORES DE ARTISTAS PROFESIONALES}

Las Academias de Bellas Artes rompieron el sistema gremial con su academicismo y control del sistema formativo de los artistas, lo que mostró su carácter vanguardista para la época (GARCÍA MELERO, 1997), que finalmente pretendía una diferenciación entre Artes liberales (proceso de enseñanza dependiente de libros) y Artes mecánicas (transmisión práctica maestrodiscípulo) (AGUIRRE, 2009). Pero, la consecución del estatus de "artista" supuso, contradictoriamente, que los artistas considerasen que habían perdido su libertad creativa frente a la normativa. Este control quedaba latente porque el profesorado debía explicar reglas básicas de geometría y aritmética y hacerlos estudiar de memoria distintos manuales relacionados (SANZ, 1990). 
Campomanes (1774) consideraba muy necesaria esa metodización de la enseñanza profesional, sin ella, el artista no podría ser considerado como tal. Sin embargo, aunque todos señalaban la importancia del estudio, ninguno hacía referencias a la forma de enseñar esa teoría histórico-artística e, incluso, técnica más específica al futuro artista... Más allá de los comentarios reseñados en epígrafes anteriores. ¿Nuevamente tendría que darse por sentada la clase magistral en las aulas de las Academias de Bellas Artes?

A pesar de una oposición que terminaría desembocando durante el siglo siguiente en la organización de las denominadas Escuelas de Artes y Oficios, los académicos consideraron que para conseguir el estatus de artista debían organizarse sesiones teóricas que propiciasen intercambios intelectuales entre los artistas y que formasen a un nivel cultural general, que permitiese mejorar su propia producción artística. Este sistema daba lugar a una formación y acreditación que dignificaba la actividad del artista, que dejaba de ser artesano; de manera que, se produjo una profesionalización del artista que obtenía un título con validez institucional (SANZ, 1990).

\section{LAS ESCUELAS DE ARTE}

La política ilustrada promocionó la fundación de escuelas y estudios relacionados con la Bellas Artes para proporcionar una cultura básica a las clases sociales medias y bajas (MONTERO, 2009): las denominadas Escuelas de Artes y Oficios. Esto daría lugar a que en el siglo XVIII se tuviese que aclarar que no todas ellas eran Reales Academias de Bellas Artes (BOSARTE, 1798). Jovellanos (1785) propuso la organización de dos centros docentes: unas escuelas de principios generales y otras de principios técnicos de cada arte. Se puede añadir otro modelo (ESCOLANO, 1982): el taller-escuela o fábricaescuela, que combinaba la producción artística con la enseñanza en artes. Villanueva (1781) se quejó de esta situación impuesta por Floridablanca, cuando la Academia de San Fernando desarrolló la doble función de Real Academia de 
Bellas Artes y Escuela de Artes. No sólo se estaba asistiendo a una estructuración de las carreras artísticas, sino que se estaba atacando a los gremios al privárseles de derechos: fue la graduación del arquitecto académico la que asestaría el golpe definitivo a la organización gremial (SANZ, 1990). En este sentido, se puede decir que, la enseñanza académica ilustrada había dado lugar a un desarrollo artístico que superaba la enseñanza gremial (AZCUE, 1991). Aunque, la problemática sobre las funciones y atribuciones de los artistas y de los artesanos todavía estaban muy lejos de resolverse: fue en 1857 cuando el Ministerio de Fomento proteja la aparición de las Escuelas de Bellas Artes, que la división entre tareas académicas y docentes quede más dividida y repartida entre las Reales Academias y las Escuelas de Artes.

En nuestro país, la enseñanza en las Escuelas estaba unida a la historia de los gremios (PEREIRA; SOUSA, 1990), siendo un aprendizaje práctico en el taller comprendido como escuela y que terminaría estancándose a nivel estéticoartístico. Uno de los motivos de ese estancamiento fue que basaban el aprendizaje en la imitación (ESCOLANO, 1982), en algo mecánico alejado de la concepción de Artes Liberales conseguida gracias a las Reales Academias (MENGS, 1780). El espíritu que movía la Escuela de Arte era paliar necesidades formativas profesionales de los obreros (DÁVILA, 1999), todo ligado a las necesidades del incipiente proceso industrializador. Así, Escolano (1982) afirmaba que la formación en los talleres eliminaba costes al proceso educativo, puesto que se generaban beneficios durante la instrucción.

Se formaba un colectivo encaminado a la acción artística directa. La cuestión es que el alumnado de las Escuelas podía ocupar puestos docentes en ellas. Ahora bien, no se han encontrado referencias significativas a la formación del docente en ellas; aunque, sí se puede decir que todo centro formativo promovido por la Ilustración llevaba implícita la importancia del proceso educativo. En este sentido sobre la importancia que tendría el estudio de la Historia el Arte, Freedman (1992) ha llegado a la conclusión que esto permitirá entender el contexto histórico-cultural en que se vive y que ha producido dichas 
obras. Por tanto, se convertiría en una forma de explicación de los fenómenos históricos y políticos que las produjeron.

\section{ANÁLISIS DE LAS REFERENCIAS DIDÁCTICAS DE LOS TRATADOS}

Campomanes (1775) consideraba muy necesaria la instrucción a nivel teórico, mediante el estudio de libros de arte para mejorar la producción de cara a la competitividad exterior. Esto viene a demostrar cómo existía un planteamiento didáctico que se consideraba obsoleto y que, por tanto, debía adaptarse o modificarse para responder a las necesidades ilustradas. Es decir, que la metodología didáctica (en cierto sentido y manera) estaba presente incluso antes de las Academias, ahora bien, siempre solía referirse a la más práctica y especulativa, y no tanto a la histórica.

Jovellanos (1785) también criticó la organización y formación de los gremios, proponiendo una estructura pedagógica diferente en la que la libertad de trabajo y de enseñanza técnica suponían un claro ataque a los gremios. De los estudios resultantes de las obras de Jovellanos, López y López (1996) recogen las actuaciones de la política ilustrada frente a los gremios que beneficiaría a las artes consideradas más nobles. También, Tello y Sanz (1994) llegan a la conclusión de que una de las principales aportaciones de las Reales Academias fue el cambio de las estructuras seculares de titulación y docencia. De hecho, uno de los principales objetivos de éstas fue la modificación de los planes de estudios para que primase la base teórica como paso previo a la ejecución práctica (JEREZ, 2005-2006); aunque, nunca se llegaba a especificar cómo debía enfocar cada docente la formación teórica-histórica de su alumnado: ¿magistral? ¿Dialógica? ¿Crítica?

Sanz (1990) consideró que, de la enseñanza individualizada en los talleres, se pasa a una docencia colectiva controlada por normas y disciplina encaminadas a desarrollar la personalidad del artista. De modo que, se podía 
hablar de cierta metodología didáctica destinada a transmitir conocimientos teóricos artísticos; ahora bien, no puede dejar de señalarse que la transmisión de estos conocimientos no iba destinada a su posterior transmisión en otras instituciones educativas de la época, sino a mejorar las características estilísticas de cada artista. Nuevamente, la transmisión de conocimientos magistralmente conduce exclusivamente a la formación práctica del artista, para satisfacer el objetivo fundamental de las Academias de Bellas Artes (formar artistas). Con todo, la primera Real Academia fundada en España perseguiría la formación en la teoría del arte y no sólo en su práctica (GARCÍA MELERO, 1997). De acuerdo con García Melero (1997), la Academia promovió una mejora del sistema pedagógico muy sistemática, que potenciaba la parte conceptual como arma didáctica, frente a las prácticas de los gremios: la reutilización de los tratados renacentistas italianos será la base teórica de la enseñanza académica; es decir, que el estudio de la Historia del Arte llevará al artista a ser considerado como tal. Por su parte, Sanz (1990) considera que fueron los principios del Despotismo Ilustrado los que llevarían a la fundación de las Academias de Bellas Artes como muestra de la confianza depositada en la eficacia de la pedagogía como instrumento de cambio social.

Será en este momento cuando se imponga el estudio con "libros de texto" (manuales), editados para garantizar mayor rigurosidad académica. Úbeda de los Cobos (1987) ha señalado cómo la voluntad de redactar y publicar libros de texto para las asignaturas teóricas terminaba perdiéndose entre otros debates que eran considerados más importantes para las distintas Academias; aunque Mengs, ya señalaría que se necesitaba saber explicar definiciones de Arte y sus reglas para comprender la profesión (DE AZARA, 1780, citado en ÚBEDA DE LOS COBOS, 1987). Los tratados españoles de este siglo respondían a las necesidades (e imposiciones) pedagógicas académicas. En el momento en que los ilustrados quieren dotar de mayor "categoría” al artista, desde los inicios de su formación, resulta lícito considerar que se necesitase una organización metodológica para las Academias. Entonces, puede considerarse que sí existía cierta pedagogía e, incluso, una sistematización de la enseñanza artística 
(AZCUE, 1991); aunque ya Mengs se quejaría sobre la ausencia de enseñanza teórica en academias como la de San Fernando (ÚBEDA DE LOS COBOS, 1987).

No todas las publicaciones relacionadas con la teoría artística tuvieron la misma acogida en la España ilustrada: primaron las ediciones realizadas por artistas españoles, frente a las de origen italiano. A pesar de ello, las Academias tenían que conocer la tratadística nacional y extranjera de la época (GARCÍA MELERO, 1997). Ésta no sólo cumplía la función de mejorar su formación práctica, sino que reforzaba su figura de artistas, sobre todo, cuando se estudiaban tratados como El pintor cristiano, y erudito, o tratado de los errores que suelen cometerse frecuentemente en pintar, y esculpir las Imágenes Sagradas (1782), de Fray Juan Interian de Ayala. En este tipo de obras, se formaba al artista para que no cometiese errores a la hora de realizar distintas advocaciones de la Virgen María y de distintos Santos, por ejemplo. Ahora bien, se trataba de manual para la formación del artista, pero no se establecían pautas didácticas para su desarrollo en el aula por parte del maestro.

En 1715, Palomino publicará El museo pictórico, y escala óptica, obra de teoría de la pintura en la que se describen los elementos esenciales para la formación artística. Aunque, pueda considerarse que se asientan ciertas ideas sobre el proceso formativo de los artistas, no será hasta 1757, cuando el Conde de Aranda dictamine que debía iniciarse un camino de publicaciones artísticas para mejorar la formación de los artistas académicos (GARCÍA MELERO, 1997): se traducen obras extranjeras, se reeditan otras y se anima a la publicación de nuevas obras nacionales para sustentar las prácticas. Se estaba creando un corpus teórico para apoyar la práctica profesional, pero sin señalar cómo debía realizarse el proceso formativo por parte del docente implicado.

El editor de la obra de Palomino (1715) comentaba la importancia de esta obra "en los estudios de los profesores españoles”, lo que deja constancia de la importancia que éstos daban al estudio teórico más allá del práctico; de forma que, transmitiesen al alumnado una formación más completa que la que estaban recibiendo en los talleres de los maestros antes de la aparición de las Academias. 
El propio Palomino, en El museo pictórico y escala óptica, estaba dando importancia a la docencia al incluir un "Índice de los términos privativos del arte de la Pintura y sus definiciones" (idem, p. 337), ya que esto permitiría al alumnado comprender lo que estaban estudiando. Se empieza a constituir esa idea de manual de estudio y no sólo de obra para los docentes al incorporarse este tipo de índices alfabéticos de términos.

La publicación de obras relacionadas con el estudio del arte fue muy profusa en España durante esta época (DE LA BANDA, 1995; SOLER, 1995), así como las traducciones y adaptaciones o compendios de los principales artistas italianos del Renacimiento: la obra de Vitrubio de 1673 llegó a España compendiada por Perrault (1761) y traducida por Castañeda. Es una obra interesante porque incluye referencias al estudio de la Historia del Arte, a nivel teórico general, que debían realizar los artistas para mejorar su práctica y su propia persona.

Aunque una obra de finales del siglo XVII, La Pintura Sabia de Fray Juan Ricci (1655) es de grandísima importancia para los artistas del siglo XVIII porque se hacen menciones a la explicación de las pinturas, lo que ya permite ver ciertas raíces de la tradición pedagógica de la didáctica de la Historia del Arte: la descripción de la obra artística como forma de aprender de ella, con un planteamiento magistral. Ahora bien, debe señalarse que el artista se nutre de ese proceso teórico-expositivo para crear a nivel práctico-experimental; y, precisamente, este documento está centrado en las referencias a la forma de enseñar en el siglo XVIII, teniendo que partirse de los principales centros de enseñanza del artista de la época (las Academias) y de los materiales que en ellas se utilizaban para enseñar a los artistas a nivel práctico (tratados y manuales), pero también teórico general.

La obra de Rieger (1763), Elementos de toda la arquitectura civil, con las más singulares observaciones de los modernos, comenta brevemente notas históricas sobre la arquitectura, para luego retomar el tema central de la obra que es la formación en los elementos fundamentales de los edificios 
arquitectónicos.

La Colección de diferentes papeles críticos sobre todas las partes de la arquitectura de Diego de Villanueva (1766) cuenta con un capítulo especialmente relevante para la formación del artista arquitecto y para el desarrollo de una metodología didáctica en la docencia de la Historia del Arte: “Sobre los estudios y conocimiento que debe tener el Arquitecto". Este tipo de referencias son las que llevarán a conocer cómo se enfocaba el proceso didáctico en las Academias y no sólo la puesta en práctica de las técnicas por parte del artista. Un año después, se edita la obra de Plo (1767), El arquitecto práctico, civil, militar, y agrimensor, dividido en tres libros, de mucha importancia para la docencia de las Academias de la época.

De Sotomayor (1776) realiza una obra para uso del profesorado de arquitectura, Modo de hacer incombustibles los edificios, en la que se pueden observar referencias a formas de tratar la arquitectura de tiempos pasados. Queda muy claro cuando en las notas al pie de la página 2 considera que "los profesores excelentes y ilustrados las leerán con imparcial benignidad”. Incluso, en la nota al pie de la página 13, se puede observar cómo la obra está realizada tras la puesta en común con un profesor de arquitectura. En esa referencia a la lectura, podría deducirse que la clase magistral donde se lee "la conferencia" o el contenido sería lo característico, puesto que así queda fijado al mencionarse de ese modo en la página 2.

En 1795, se traduce la obra de Simonin, Tratado elemental de los cortes de cantería o Arte de la montea, que muestra las principales técnicas para el trabajo de la piedra, pero tiene especial importancia porque deja traslucir la importancia de la formación teórica en el arte de la montea.

Muy importante es la obra de Bails (Elementos de matemáticas) (1796), que otorga especial importancia a la figura del docente de las Academias como productor de obras de estudio. Ya estaba asentando un sistema que continuaría a lo largo de los siglos: el profesorado edita manuales de texto para la superación de las materias, práctica muy habitual en la actualidad. Presenta 
múltiples referencias didácticas y a la importancia de la Historia del Arte en la formación artística. Aunque publicada en 1800, la obra de Ceán Bermúdez (1800), Diccionario histórico de los más ilustres Profesores de las Bellas Artes en España, comprendía las principales figuras artísticas de las Reales Academias, entre otras de siglos anteriores.

Las referencias didácticas en estos tratados dan muestra de cómo debía orientarse la formación del artista y, por tanto, el camino que debía seguir el docente. Perrault (1761) en su compendio de la obra de Vitrubio, muestra el interés de éste por una formación del artista más allá del elemento práctico. Esto supone el estudio de la Historia del Arte, porque en la página 11 del prefacio se menciona que un elemento de estudio fueron los primeros inventores de las órdenes de arquitectura griegas; ahora bien, deducimos tras la lectura del documento que esta parte era impartida en la línea medievalista de la clase magistral como paso previo al desarrollo práctico, que era lo que realmente importaba al artista en formación. Esa misma idea de impartición magistral se puede deducir de la obra de Rieger (1763), puesto que no sólo comenta los fundamentos que el arquitecto debe conocer para la práctica correspondiente, sino que se centra en detalles más teóricos de definiciones sobre conceptos propios de la arquitectura que no tendrían necesidad de estar, pero que considera relevantes para la formación completa; ahora bien, siempre parece sobreentenderse que se transmitirán magistralmente, porque no se habla de enfoques críticos-reflexivos, ni dialógicos en la línea socrática.

Villanueva (1766) en Colección de diferentes papeles críticos sobre todas las partes de la Arquitectura, señala la necesidad del estudio de otras materias relacionadas con la arquitectura. Su organización de los estudios de arquitectura deja constancia de la pedagogía de la época, ya que divide en dos grandes bloques la formación del arquitecto: elementos de necesidad absoluta y de adorno. En su Carta V "Sobre los estudios, y conocimientos que debe tener el Arquitecto" viene a decirnos que el arquitecto tiene que ser instruido en el "Arte de formar, adornar y demostrar" (idem, p. 48). Así, se comprende que el 
profesorado de las Academias tuviese que realizar un importante trabajo de la teoría del arte para que el arquitecto fuese una persona instruida, aunque esta educación a través de la teoría del arte fuese expositiva.

Plo (1767), en la página 3 de El arquitecto práctica, civil, militar, y agrimensor, dividido en tres libros, deja bien claro que es "esta Obra una instrucción para los Profesores de Arquitectura Civil, Militar”. Si bien esto no sea una referencia a cómo debía ponerse en práctica en el aula, queda claro que es una obra que teóricamente debía apoyar la labor docente de la época.

El tratado Modo de hacer incombustibles los edificios de Sotomayor (1776), presenta múltiples referencias a la figura del docente de arquitectura y su papel como transmisor de conocimientos, ahora bien, no se mostraba cómo debía transmitirlos en el aula. Esto queda muy claro cuando en las notas al pie de la página 2 considera que "los profesores excelentes y ilustrados las leerán con imparcial benignidad". Incluso, en la nota al pie de la página 13, se puede observar cómo la obra está realizada tras la puesta en común y comentario de determinados principios de la arquitectura con un profesor de arquitectura.

En 1789, la obra Arcadia pictórica en sueño: alegoría o poema prosaico sobre la teórica y práctica de la pintura mencionaba en su editorial la importancia que la obra podía tener para el profesorado de las Academias y de las Escuelas. Sin embargo, sucede como con otras comentadas en párrafos anteriores: se centran en la formación técnica del futuro artista, sin dar pistas sobre la utilización del manual por parte del profesorado.

Como en la obra de Villanueva (1766), Simonin (1795) presenta una división entre los elementos teóricos más relacionados con las posteriores prácticas y los teóricos que se pueden considerar relacionados con la Historia del Arte, propiamente dicha. Esto se puede ver cuando en la página primera de la obra comenta "Se dá también una idea del Arte de la Montea y su importancia; de su historia y progresos". Partiendo del hecho de que los tratados teóricos eran trabajados en el aula desde la exposición magistral, se comprende la necesidad de la obra de Simonin (1795), en la que hace referencia 
a las principales obras que dan fe de la importancia de estudiar detalladamente este arte.

Así, en Elementos de Matemáticas de Bails (1796), se recomendaba el estudio de materias como la Historia del Arte como forma de garantizar los conocimientos necesarios para la formación completa del artista. Esto muestra cómo se impartía la docencia de la Historia del Arte en este período, acorde con la línea magistral actual. Esta forma de educar al futuro artista en conceptos históricos a través de la edición de manuales o de tratados para utilizar en las aulas de las Academias y las Escuelas de Arte se multiplicó durante el siglo XVIII; aunque, el análisis desde una investigación centrada en las referencias a la didáctica de la Historia del Arte muestra cómo no han quedado suficientes referencias que puedan llevar a pensar en un sistema docente más allá de la clase magistral para los conceptos de índole histórica artística.

Pero, la inclusión de una materia específicamente destinada al estudio de la Historia del Arte como tal no se verá en España hasta el siglo XIX y en las Escuelas de Artes: la asignatura de "Teoría e Historia de las Bellas Artes" se introdujo en las Escuelas de Bellas Artes con un manual de Manjarrés y Bofarull, destinado a suplir la toma de apuntes en el aula para poder explicar y discutir los puntos más interesantes de esta temática (CABALLERO, 2000). De acuerdo con Rodríguez-Samaniego (2013), no será hasta el siglo XIX cuando se modernice la docencia en materia artística; porque no puede olvidarse que, la Historia del Arte era todavía una ciencia en formación durante la segunda mitad del siglo XIX (CABALLERO, 2000). Muestra de esto sería el hecho de que autores como Carducho, con sus Diálogos de la pintura, recupera la enseñanza dialógica que ya utilizarían los autores de la Antigüedad Clásica en Grecia (Sócrates, etc.), pero para ello hay que esperar hasta la segunda mitad del siglo XIX (su obra fue publicada en 1865). España siempre ha ido con bastante retraso respecto a otros países, tanto en la llegada de las tendencias artísticas como en las pedagógicas.

Muñoz y Ruiz (2003) han estudiado el valor didáctico otorgado a las 
artes en determinadas épocas. Esto permitiría entender y justificar el hecho de que, finalmente, los ilustrados considerasen lógica la fundación de Academias donde los artistas se formasen de una forma completa, puesto que podían llegar a enseñar a su vez y enseñar a través de su arte al pueblo menos instruido. En relación con esto, Rodríguez Gutiérrez de Ceballos (1992) ha mostrado cómo la formación tradicional que se recibía en los gremios y talleres no respondía más que al aprendizaje de una serie de "recetas" rutinarias, sin estudio de manuales ni tratados que pudiesen mejorar su formación a un nivel teórico, considerado igualmente importante que el práctico por parte de las Academias.

No se han encontrado referencias específicas en los tratados que den pie a pensar que la docencia de la Historia del Arte fuese de una forma diferente a la que ha llegado hasta nuestros días en las universidades: la clase magistral. Actualmente, se puede decir que este modelo habría quedado obsoleto para la docencia en los niveles previos a la Universidad, debido a las características del alumnado actual: Peláez (2008) propone la realización de pósteres didácticos para facilitar la comprensión del vocabulario artístico. Esta opción "tradicional” (porque recurre a cartulinas para realizar pósteres) dentro de las nuevas posibilidades didácticas, deja ver que el alumnado del siglo XXI necesita otras metodologías que puedan dar respuesta a sus necesidades.

Blanco y Mazoy (2010) consideran que, gracias a El museo pictórico y escala óptica de Palomino, se estimula la creación de materiales visuales para la didáctica artística. Estas autoras están mostrando la necesidad de plantear otros materiales didácticos para garantizar la comprensión de las obras de arte al alumnado del siglo XXI, alejándose de la tradicional clase magistral. También alejada de ésta, Cao (1988) plantea partir del análisis retórica de la obra de arte como camino de numerosas dificultades docentes. Pero, la demanda de una mayor practicidad en la enseñanza de la Historia del Arte es algo que ya Caballero (2000) señala que pasaba incluso en el siglo XIX; y en los primeros años del siglo XXI, Ortega (2002) también insiste en la necesidad de una preparación adecuada a las exigencias del futuro docente y del alumnado. Ávila 
(1999) ya señalaba la importancia del consenso respecto a lo que debe enseñar el profesorado de Historia del Arte, que siempre debería tener en cuenta aquello que se necesita aprender y enseñar del arte.

Una propuesta interesante es la de Rovira (2011), que garantiza el aprendizaje de los elementos característicos del arte griego de índole más teórica. Ahora bien, la etapa de Bachillerato va encaminada a la superación de una prueba de acceso a la universidad, lo que determina (desgraciadamente) un modelo de examen y, por tanto, de trabajo. Esto supone que la explicación en el aula pueda caer en la clase magistral, perdiéndose la importancia que debería otorgarse a la comprensión sobre cómo se construye el conocimiento histórico del arte por parte del alumnado (FREEDMAN, 1992). Aunque, parece ser que la docencia de Historia del Arte ha terminado por rechazar la apropiación formal de significados y, ahora ya, parte de las ideas artísticas previas del alumnado (ORTEGA, 2002).

Quizá la mayor problemática para la determinación de una metodología didáctica para esta disciplina, también, se deba al poder ejercido por los libros de texto, en este sentido, se cuenta con las investigaciones de Guillén (2012), que ha profundizado en el análisis comparado de distintas editoriales y sus enfoques sobre los procedimientos relacionados con la didáctica de la Historia del Arte. Si se parte de que el objetivo de la Historia del Arte es el análisis de las obras artísticas (GUILLÉN, 2010), los libros centrados en esta disciplina deberían presentar formas de facilitar dicho análisis y promover un aprendizaje no sujeto a la explicación teórica-magistral. Esto estaría en la línea de lo que se comentó que sucedía en las Academias.

\section{CONCLUSIONES}

Las Reales Academias de Bellas Artes se convirtieron en centros educativos artísticos y promotores de la educación artística, al partir del 
principio de que el artista, para ser considerado como tal, debía contar con una importante formación teórica que le permitiese razonar sobre los motivos de selección de tal o cual elemento artístico. Y, esto hace una clara referencia a la teoría del Arte, a la Historia del Arte, que, si bien se consideraba teórica y enlazada con la tradicional clase magistral, bien cierto es que terminaba desembocando en la práctica de las Bellas Artes. Así, se abría el camino al terreno de lo "práctico", en cuanto a la docencia en Historia del Arte, que se terminaría imponiendo en las aulas de finales del siglo XX y principios del XXI.

Otro punto objeto de estudio fue la relación entre la enseñanza impartida en la Academia, la relevancia del estudio teórico y la consideración del artista. El análisis realizado vino a demostrar que las Academias debían mucho a la Historia del Arte como disciplina; e, incluso, no se puede dejar de afirmar que la Historia del Arte como tal, aportó mucho a su vez al desarrollo de las Academias ilustradas porque les permitió dotar de un valor diferente al artista. En ellas, el artista dejaba de ser formado en su vertiente práctica y especulativa y, gracias a esa formación teórica histórico-artística, pasaba a ser formado desde una vertiente histórica y teórica. En este documento se ha tratado de mostrar qué referencias presentan los distintos manuales respecto a la forma de enseñar esos conocimientos teóricos relacionados con la Historia del Arte, con los períodos, con las características, con la evolución de las técnicas y los motivos de ella.

Aunque, si en las Academias griegas la dialéctica era una metodología habitual, en la docencia en Arte no se vio reflejada en ninguno de los documentos estudiados, salvo en una obra citada perteneciente al siglo XIX. Así, se ha demostrado que las referencias a la didáctica encontradas han repercutido en el desarrollo de la didáctica de la Historia del Arte posterior: su transmisión ha quedado limitada a la exposición magistral. Tras todo lo expuesto, se puede decir que ha quedado demostrada la importancia de las Reales Academias de Bellas Artes en el desarrollo de una primitiva didáctica de la Historia del Arte, aunque esta haya mostrado que lo magistral primaba sobre lo dialógico como 
proceso de enseñanza/aprendizaje de la Historia del Arte necesaria para los artistas prácticos.

\section{BIBLIOGRAFÍA}

AGUIRRE, María Esther. Los senderos del arte, la formación y la educación artística. Notas para un deslinde. Revista Educación y Pedagogía, v. 21, n. 55 , p. 15-29, 2009.

ARAÑO, Juan Carlos. La enseñanza de las Bellas Artes como forma de ideología cultural. Arte, Individuo y Sociedad, v. 2, p. 9-30, 1989.

ARCE, Celedonio Nicolás. Conversaciones sobre escultura: compendio histórico, teórico y práctico de ella. Pamplona: José Longas, 1786.

ÁVILA, Rosa María. Aportaciones al conocimiento profesional sobre la enseñanza y el aprendizaje de la Historia del Arte. Sevilla: Universidad de Sevilla, 1998.

ÁVILA, Rosa María. La construcción del conocimiento escolar. Una propuesta de secuenciación de contenidos para la enseñanza de la Historia del Arte.

Investigación en la Escuela, n. 39, p. 39-48, 1999.

ÁVILA, Rosa María. El papel de la Historia del Arte en el currículum. Íber, v. 29, p. 67-80, 2001.

AZCUE, Leticia. El Museo de la Real Academia de Bellas Artes de San Fernando: la escultura y la Academia. Madrid: Universidad Complutense de Madrid, 1991.

BAILS, Benito. Elementos de matemática. Madrid: Imprenta de la Viuda de Joaquín Ibarra, 1796.

BÉDAT, Claude. L'Académie des Beaux-Arts de Madrid (1744-1808).

Toulousse: Association des publications de l'Université de Toulouse-Le Mirail, 1974 .

BLANCO, Carmen; MAZOY, Ana. En torno a una investigación en didáctica artística: enseñanza-aprendizaje del arte con nuevos materiales visuales.

Revista de Didácticas Específicas, v. 2, p. 6-24, 2010.

BLANCO, Carmen. Variaciones para una didáctica de la Historia del Arte en la 
Educación General Básica. Boletín de Arte, v. 4-5, p. 51-75, 1984.

BLANCO, Carmen. Hacia una cultura universal: algunos precedentes en la enseñanza de la Historia del Arte. Tendencias Pedagógicas, n. 2, p. 127-134, 1998.

BOSARTE, Isidoro. Discurso sobre la restauración de las Bellas Artes

en España. Disertación sobre el estilo que llaman gótico en las obras de Arquitectura. Madrid: Imprenta de la Viuda de Ibarra, 1798.

BRIZGUZ, Atanasio Genaro. Escuela de arquitectura civil. Valencia: Oficina de José de Orga, 1795.

CABALLERO, Maria Rosario. La Historia del Arte en la enseñanza secundaria: perspectiva histórica y posibilidades de futuro. Imafronte, n. 8-9, p. 51-6o, 1992-1993.

CABALLERO, Maria Rosario. El primer Manual de Historia del Arte con destino al Bachillerato. Su autor: Hermenegildo Giner de los Ríos. Imafronte, v. 15, p. 17-27, 2000.

CALAF, Roser. La enseñanza de la Historia del Arte: entre la borrosidad y la realidad posible. Íber, n. 8, p. 17-24, 1996.

CÁMARA, Alicia. La arquitectura militar del Padre Tosca y la formación teórica de los ingenieros entre Austrias y Borbones. In: CÁMARA, Alicia (Ed.). Los ingenieros militares de la monarquía hispánica en los siglos XVII Y XVIII. Madrid: Fernando de Villaverde Ediciones, 2005. p. 133-158.

CANDAU, María Jesús. Percepción y didáctica del comentario de arte. Íber, v. 49, p. 74-82, 2006.

CANTONERO, Juan. Una arqueología de la mirada o qué Historia del Arte estamos enseñando. Campo Abierto: Revista de Educación, v. 21, p. 83-96, 2002.

CAO, Marián. La retórica visual como análisis posible en la didáctica del arte y de la imagen. Arte, Individuo y Sociedad, v. 10, p. 39-62, 1998.

CASTAÑEDA, Ana María. Historia del Arte: política educativa en la enseñanza secundaria y bachillerato. Desarrollo de una unidad didáctica. Granada: Editorial Alfacar, 2003.

CASTAÑER, Xesqui. Transferencias terminológicas y conceptuales de la literatura artística española del siglo XVIII: Antón Rafael Mengs y Preciado de la Vega. In: RODRÍGUEZ ORTEGA, Nuria; TAÍN GUZMÁN, Miguel (ed.). 
Teoría y literatura artística en España. Málaga: Ministerio de Economía y Competitividad y Proyecto Atenea, 2013. p. 81-82.

CASTILLO, Miguel Ángel; RIAZA, Mónica. Entre el Barroco y el Neoclasicismo: la Academia de Bellas Artes de San Fernando y las últimas empresas constructivas de los Borbones en América. In: Actas del III Congreso Internacional del Barroco americano: territorio, arte, espacio y sociedad. Sevilla: Universidad Pablo de Olavide, 2001. p. 708-724.

CORZO, José Ramón. Las academias de Bellas Artes de Andalucía. Su origen, historia y organización actual. Temas de estética y arte, v. 25, p. 206-225, 2011.

CRESPO, Daniel. El caso de la literatura artística. Cuadernos de Historia Moderna, v. 32, p. 31-60, 2007.

DÁVILA, Paulí. Las escuelas de artes y oficios en el País Vasco, 1879-1929. Historia de la Educación, v. 18, p. 191-215, 1999.

DE AYALA, Fray Juan Interian. El pintor cristiano, y erudito, o tratado de los errores que suelen cometerse frecuentemente en pintar, $y$ esculpir las imágenes sagradas. Madrid: Joaquín Ibarra, 1782.

DE LA BANDA, Antonio. La historiografía artística andaluza en los siglos XVIII y XIX. Laboratorio de Arte, v. 8, p. 207-216, 1995.

DE LA VEGA, Francisco Preciado. Arcadia pictórica en sueño: alegoría o poema prosaico sobre la teórica y práctica de la pintura. Madrid: Antonio de Sancha, 1789.

DE SOTOMAYOR, Joaquín. Modo de hacer incombustibles los edificios. Madrid: Oficina de Pantaleón Aznar, 1776.

ESCOLANO, Agustín. El origen de la escuela técnica moderna en España. Historia de la Educación, v. 1, p. 169-191, 1982.

ESCUDERO, José Antonio. La creación de las Reales Academias en España. Reunión de las Academias Europeas celebrada en el Instituto de España. 1992.

FEIJOO, Benito Jerónimo. Teatro crítico universal. Madrid: Joaquín Ibarra Impresor, 1778.

FRANCÉS, José. Acta de la sesión conmemorativa del II Centenario de la fundación de la Real Academia de San Fernando, celebrada el 13 de junio de 1952. Academia: Boletín de la Real Academia de Bellas Artes de San Fernando, 
v. 3, p. 275-278, 1952.

FREEDMAN, Kerry. La enseñanza del tiempo y del espacio: comprensión de la Historia del Arte y de la herencia artística. Revista de Educación, n. 298, p. 81-88, 1992.

GARCÍA LÓPEZ, David. Siguiendo a Palomino: biografías de artistas durante el siglo XVIII español. In: RODRÍGUEZ ORTEGA, Nuria; TAÍN GUZMÁN, Miguel (Ed.). Teoría y literatura artística en España. Málaga: Ministerio de Economía y Competitividad y Proyecto Atenea, 2013. p. 63-64.

GARCÍA MELERO, José Enrique. El arquitecto académico a finales del siglo XVIII. Espacio, Tiempo y Forma, v. 10, p. 161-216, 1997.

GARCÍA MENÉNDEZ, Bárbara. La biblioteca del escultor Juan de Villanueva y Barbales (1681-1765). BSAA arte, v. LXXVI, p. 215-240, 2010.

GUILLÉN, Mercedes. El análisis de una obra de arte: valoración del alumnado y del profesorado sobre la enseñanza de este procedimiento en los libros de texto. Clío, v. 36, p. 1-18, 2010.

GUILLÉN, Mercedes. Libros de texto y enseñanza de la historia del arte. Íber, n. 71, p. 93-99, 2012.

HERNÁNDEZ, Francisco. El patrimonio cultural: la memoria recuperada. Gijón: Ediciones Trea, 2002.

JEREZ, Felipe. El estudio de la anatomía en la formación académica de los artistas durante el período ilustrado. Aportaciones de algunos pintores y grabadores valencianos. Ars Longa, v. 14, n. 15, p. 217-231, 2005-2006.

JOVELLANOS, Gaspar. Informe dado a la Junta de Comercio y Moneda sobre el libre ejercicio de las artes. Madrid: M. Rivadeneyra ImpresorEditor, 1785 .

JUANOLA, Roser; CALBÓ, Muntsá. Lo que no es nuevo puede ser actual: hacia distintos puntos de mira de la didáctica del arte. Íber, v. 49, p. 26-37, 2006.

LEÓN, Francisco José; SANZ, María Virginia. Estética y teoría de la arquitectura en los tratados españoles del siglo XVIII. Madrid: Consejo Superior de Investigaciones Científicas, 1994.

LÓPEZ, Juan Jesús; LÓPEZ, Miguel Luis. Artes y oficios artísticos en Granada a mediados del siglo XVIII. Espacio, Tiempo y Forma, Serie VII, Historia del Arte, v. 9, p. 157-188, 1996. 
MARTÍN, Juan José. La escultura neoclásica en la Academia de San Fernando. Siglo XVIII. In: FERNÁNDEZ, Xosé (Coord.). Experiencia y presencia neoclásicas: Congreso Nacional de historia de la arquitectura y del arte. La Coruña: Servicio de Publicaciones de la Universidad de La Coruña, 1991. p. 1323.

MENGS, Antonio Rafael. Carta a un amigo sobre la constitución de una Academia de Bellas Artes. In: AZARA, José Nicolás (Ed.). Obras de Mengs. Madrid: Imprenta Real de la Gazeta, 1780. p. 391-393.

MONTERO, Ana María. La creación de la Escuela de Artes y Oficios de Sevilla y la formación de la clase obrera a finales del siglo XIX. Revista Fuentes, v. 9, p. 166-178, 2009.

MORAL, Ana María. Honor, vileza y honra de los oficios mecánicos en el siglo XVIII. Baetica - Estudios de Arte, Geografía e Historia, v. 18, p. 379-385, 1996.

MUÑOZ, Luz; RUIZ, María Gracia. El arte de enseñar a través del arte: el valor didáctico de las imágenes románicas. Educatio Siglo XXI, v. 20-21, p. 227244, 2003.

NAVARRETE, Esperanza. La Real Academia de Bellas Artes de San Fernando cuando Goya era profesor (1785-1797). In: Goya y su contexto: actas del Seminario Internacional celebrado en la Real Academia de Bellas Artes de San Fernando 2011. Madrid: Institución Fernando el Católico, 2013. p. 317-341.

ORTEGA, Natividad. Didáctica de la Historia del Arte. Almería: Universidad de Almería, 2002.

PALMA, Dolores. Las escuelas patrióticas creadas por la Sociedad Económica Matritense de Amigos del País en el siglo XVIII. Cuadernos de Historia Moderna y Contemporánea, v. 5, p. 37-55, 1984.

PALOMINO, Antonio. El museo pictórico y escala óptica. Madrid: Imprenta de Sancha, 1715 .

PELÁEZ, José Enrique. Didáctica de la historia del arte: Materiales y técnicas escultóricas. In: Actas del II Congreso Internacional de Lengua, Literatura y Cultura de e/le: teoría y práctica docente. Onda: JMC, 2008. p. 229-240.

PEREIRA, Fernando y Sousa, José. El caso compostelano. Historia de la educación, v. 9, p. 219-232, 1990.

PERRAULT, Claude. Compendio de los diez libros de arquitectura de 
Vitrubio. Madrid: Imprenta de Gabriel Ramírez, 1761.

PLO, Antonio. El arquitecto práctico, civil, militar, y agrimensor, dividido en tres libros. Madrid: Imprenta de Pantaleón Aznar, 1767.

RIEGER, Cristián. Elementos de toda la arquitectura civil. Madrid: Imprenta de Joachin Ibarra, 1763.

RÍOS, Sonia. Aprendizaje artístico vs análisis cualitativo. Los "Diálogos" de Carducho y el arte de formular preguntas. In: RODRÍGUEZ ORTEGA, Nuria; TAÍN GUZMÁN, Miguel (Ed.). Teoría y literatura artística en España. Málaga: Ministerio de Economía y Competitividad y Proyecto Atenea, 2013. p. 107-109.

RODRÍGUEZ DE CAMPOMANES, Pedro. Discurso sobre el fomento de la industria popular. Madrid: Imprenta de Sancha, 1774.

RODRÍGUEZ DE CAMPOMANES, Pedro. Discurso sobre la educación popular de los artesanos y su fomento. Madrid: Imprenta de Sancha, 1775 .

RODRÍGUEZ GUTIÉRREZ DE CEBALLOS, Alonso. El siglo XVIII: entre tradición y academia. Madrid: Sílex, 1992.

RODRÍGUEZ-SAMANIEGO, Cristina. La educación artística en la Escuela de Bellas Artes de Barcelona durante el siglo XIX. El caso de la escultura. Arte, Individuo y Sociedad, v. 3, n. 25, p. 494-507, 2013.

ROVIRA, Montserrat. Diseño de una prueba de corrección objetiva para Arte Griego: Arquitectura. Clío, v. 37, p. 1-26, 2011.

SÁNCHEZ DE ANDRÉS, Leticia. Manuales de origen krausista para la enseñanza de la estética y la historia del arte y de la música en los institutos de bachillerato. Árbor - Ciencia, Pensamiento y Cultura, v. 187, n. 749, p. 1-11, 2011.

SANZ, María Mercedes Virginia. Docencia y titulación en las Reales Academias. Control académico en la construcción. Anales de Historia del Arte, v. 2, p. 155-177, 1990.

SCHLOSSER, Julius. La literatura artística. Madrid: Cátedra, 1986.

SIMONIN. Arte de la Montea. Madrid: Imprenta de la Viuda de Josef García, 1795 .

SOLER, Ramón. Libros de arte en bibliotecas de artistas españoles (siglos XVI- 
XVIII): aproximación y bibliografía. Locus Amoenus, v. 1, p. 145-164, 1995.

TAPIE, Víctor. Barroco y Clasicismo. Madrid: Cátedra, 1978.

TOSCA, Tomás Vicente. Compendio de matemáticas. Valencia: Antonio Bordazar, 1757.

TREPAT, Cristófol. Los campos de aprendizaje y la historia del arte. Íber, v. 43, p. 44-57, 2005 .

ÚBEDA DE LOS COBOS, Andrés. Propuestas de reforma y planes de estudio: la influencia de Mengs en la Real Academia de Bellas Artes de San Fernando.

Archivo Español de Arte, n. 240, p. 447-461, 1987.

VALZANIA, Francisco Antonio. Instituciones de arquitectura. Madrid: Imprenta de Sancha, 1792.

VEGA, Jesusa. Ciencia, arte e ilusión en la España ilustrada. Madrid: CSIC, 2010.

VILLANUEVA, Diego. Colección de diferentes papeles críticos sobre todas las partes de la Arquitectura. Valencia: Benito Monfort, 1766.

VILLANUEVA, Juan. Sentir sobre el nuevo arreglamiento, que se premedita establecer para la aprobación de Maestros de obras y Arquitectos, y la recepción de Académicos. Madrid: Archivo de la Real Academia de Bellas Artes de San Fernando, 1781.

WINCKELMANN, Johann Joachim. Historia del arte de la Antigüedad. Madrid: Ediciones Akal, 1764 (edición de 2011).

MARIA DEL MAR BARNABÉ VILLODRE é professora contratada doutora na Universidade de Valência. Ela praticou como professora em diferentes centros educacionais e em diferentes especialidades, incluindo História da Arte. Atualmente, ele realiza seu trabalho de professora no Departamento de Didática da Expressão Musical, Plástica e Corporal da Faculdade de Ensino da Universidade de Valência. Seus interesses de pesquisa concentram-se na atenção à diversidade funcional e cultural dos processos musicais. Faz parte do Grupo de Pesquisa COS.

E-mail: maria.mar.bernabe@uv.es

(D) http://orcid.org/0000-0001-8983-6602 
Recebido em: 08 de julho de 2019

Aprovado em: 03 de novembro de 2019

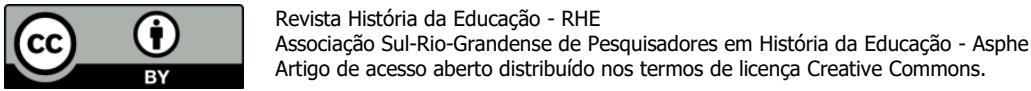

